\title{
Conflicts and context in managing the closure of a large psychiatric hospital
}

\author{
LoRna McKeE, Principal Research Fellow, Centre for Corporate Strategy and Change, \\ University of Warwick
}

The slow progress in providing community-based care for mentally ill people and thus closing large psychiatric institutions has been well researched and documented. The enquiries have typically sought to demonstrate the gap between national policy intent and reality and have highlighted the structural, financial and organisational barriers to achieving new forms of service provision. ${ }^{1}$ Equally, an important recent study has shown that there are marked intra-Britain differences in how the assumed unitary national policy is interpreted and implemented. ${ }^{2}$ There is general agreement that the present 'statutory framework' inhibits radical service change and, furthermore, that centralised planning, joint-working, joint-planning mechanisms are flawed and underpinned by a poorly formulated financial and manpower strategy. ${ }^{1}$ Some management 'process' factors have also been isolated such as the presence/ absence of clear leadership and committed local champions of change'. ${ }^{1.3}$ The issue of 'interprofessional tensions' has been only briefly alluded to, with even less recognition of how the other powerful organisational groups interrelate. Certainly, there has been little ethnographic detail of how these tensions between dominant groups are played out at a local level or indeed impinge on local decision-making and progress. More typically, existing accounts of the closure of the large institutions have had a structuralist bias, with more emphasis upon the impact of regional and national policy and on the machinery of collaboration than on internal politics or the effects of local power relations. ${ }^{3}$

As a corrective to this tendency to ignore internal dynamics, this paper looks at the significance of one strand of inter-organisational relationships, the management-clinician interface, and will illustrate, using detailed case study material from one hospital closure, how these internal relationships influence and constrain action. The data upon which the paper rests have been gathered as part of a larger investigation into the 'Management of Change in the NHS' ' based at the Centre for Corporate Strategy and Change at the University of Warwick and directed by Professor Andrew Pettigrew, who has published widely on the management of strategic change in a range of public and private sector organ- isations. The study is funded by eight NHS regions and the NHSTA.

The intention in this paper is not to decry the importance of the external impediments to achieving care in the community policies but rather to complement earlier analyses with a deeper appreciation of internal context and management process. ${ }^{4}$ Case study analysis is especially suited to mapping out how various interested parties interpret, perceive and respond to top-down policies and how they enable or disable the accomplishment of those policies within a particular institution. Although less well-equipped to provide generalisable measures the case study does generate transferrable analytic categories. In the present study, the emphasis has been on understanding the unique characteristics of the interior of each case study organisation, its codification system; its elites; its decision-making process; its culture; its selfimage and history. Our broad thesis is that it is the way that these internal and external structural and process factors combine that shapes the rate and pace of change. ${ }^{5}$ For the purpose of the paper, the process factors will dominate the analysis, for this remains the area of greatest ignorance.

The paper will begin by exploring the characteristics of the management-clinician relationship in one large psychiatric hospital scheduled to close in 1992. Points of tension and dissension will be highlighted and the gap between clinical and management perspectives illuminated. Secondly, the paper will detail some of the antecedent conditions for change in psychiatric services and point to the importance of considering the context of change. Lastly, the paper will assess whether care in the

*In this case study, 56 in-depth, formal interviews were conducted with a range of personnel drawn from different tiers of the organisation, different professions, with the inclusion of relevant external agencies. Site visits were extensively undertaken and key meetings were attended, including meetings of all Clinical Teams, Unit Management Board and Joint Planning Team. Informal interviews and informal observations were also carried out over a protracted period spent within the organisation. Relevant documentation was accessed and analysed, including minutes of key meetings and policy and strategic documents. 
community represents a radical shift in practice and ideology for clinicians and whether in fact it could herald the demedicalisation of the problem and the disenfranchising of consultant psychiatrists.

\section{Doctors and managers: who is changing?}

Projected hospital closure and the transfer of services from one institutional base to a more diffuse arrangement represents a radical organisational change. It implies changes in beliefs, in philosophies, resourcing, expertise, practice and relationships. There is within such a scaled change the scope for considerable conflict and decision-making becomes highly politicised. ${ }^{6.7 .8}$ The data drawn from the case study hospital suggest that this conflict is especially acute between consultant psychiatrists and general managers and that it hinges around: perceptions of where the pressure for change comes from; definition of the problem; desired objectives; methodology; motives and control of outcomes. Essentially, there is a clash between medical and management perspectives; and with the introduction of general management and timed-costed objectives for managers, there is, at its extreme, a potentially heightened struggle over sovereignty of the care of the mentally ill.

\section{The pressure for change}

The management literature suggests that the origin of proposed change is an influential factor in determining the result, whether top-down or bottom-up; managerially- or professionally-led. ${ }^{9}$ It would seem this is an area where perceptions differ and where one party can underestimate the other's contribution. In this particular case study, the closure of the hospital was of prime importance to the Region concerned. An expected closure date had been set and the future services in a number of Districts were contingent upon its success. The Annual Review process plus the usual strategic planning documents endorsed the closure intention and spelt out the imperative to provide community-based alternatives. From 1982 onwards, directives from the top tiers were united with mechanisms set up to provide incentives to speed up the run-down of the large institutions and the provision of community services. The real pressures to advance care in the community were intensifying over this period, backed up by Regional and local-based targets on ward closures and the Region's withdrawal of monies from the teaching hospital. The appointment of a Unit General Manager in 1986 further sharpened the process and the District began to develop a timed-costed retraction plan for its hospital.

While these factors all add up to an apparently strong managerial lead and to a top-down change process, it is useful to track back to where the impetus for the change had originated; and, importantly, to how the different actors see their place in this history. Conflict over ownership of the original policy and the leadership of it is about the legitimacy and authority of the different actors and about how this pans out over time. $^{10}$

The consultant psychiatrists interviewed in the present study felt that their initial pioneering role as a profession in introducing care in the community was being denied and denigrated by the local general managers. Many of the clinicians saw the shift away from institutional care as 'their' initiative and cited the long catalogue of clinical breakthroughs from the 1930s onwards which had enabled more and more mentally ill people to be treated outside the asylum. They found it ironic to be perceived by managers as laggards and as resistant to community schemes. The conflict over who are the 'change leaders' and the source from which the community care policy springs is encapsulated in the extracts below. It is important to note that the role of social and medical change is endorsed while managerial direction is dismissed.

"We always argued that it was the consultants in this hospital who tried to get the move going: although now I think these people (managers) think that it is the consultants who are trying to block it. I think what the consultants are concerned about is that it is done properly, i.e. that the exercise isn't merely the emptying of the mental hospitals, but the exercise is the careful and accurate reprovision of the services elsewhere."

\section{Consultant Psychiatrist}

Another consultant comments on the reduction of patient numbers in the hospital from over 3000 to under 1000:

\footnotetext{
"One of the jokes about the current fanfare of trumpets for community care is that it neglects the fact that for years community care for the vast majority of psychiatric patients has been occurring. When we talk about patients here we are talking about the tip of the iceberg. . . The main reason it (the reduction) occurred are effective treatments and the 1959 Mental Health Act. Plus the growing trend to open door policies and the recognition of the individual patients which grew out of the burgeoning Civil Rights movement in the States. The changes were social and medical, they were not managerial or organisational."
}

Consultant Psychiatrist 
312

When managers were asked from where they saw the pressure to provide care in the community services stemming (and congruently the hospital closure), they were much more likely to tie it to policy imperatives and to managerial action such as the review process than to clinical or scientific advances. A senior officer confirms this thrust saying:

"As far as I am concerned it's always been a closure ... If one goes back in history, I suppose it was round about 1982 that the first indicators to develop an alternative regional strategy and policy became apparent."

\section{District Officer}

The common view of a number of managers interviewed here was that the clinicians' part in the service change ranged from, at best, passive to, at worst, obstructive. Others voiced the opinion that they were 'reactive', prone to 'stonewall', 'bugger things up'. They also cited examples of where consultants behave in a negative or self-protective fashion, guarding bed norms and resisting management decisions. In general, the managers in this case tended to play down or discount the historical role of clinicians in bottom-up change in services for the mentally ill. The managers were more influenced by their day to day experience of the clinicians which was described as less than innovative or supportive of change. The equivocacy of consultant psychiatrists was also felt to impede the move to care in the community. As one relatively new manager said:

"Their attitude doesn't seem constructive and forward-looking: but then that seems to be the case with all clinical teams.... Things are happening in spite of the clinicians, the clinicians aren't lending their whole-hearted support."

\section{Unit Officer}

Clinicians were also accused by managers of hiding behind concepts of clinical freedom or autonomy whenever unpalatable decisions had to be taken. Their refusal to fit into a line management structure was felt to be a considerable constraint and to thwart the success of general management. These frustrations surface in the comments of a unit officer:

"They (clinicians) want the status of being part of the Unit Management Group, being at all the meetings, but they don't want to make decisions. And they certainly don't want to be in a situation where they are overruled.... The consultants as I see it cannot cope with that sort of thing. If they
Bulletin of the Royal College of Psychiatrists

offer advice and it's not taken, people begin to die, it becomes a resignation issue!"

Unit Officer

\section{Whose timetable?}

This collision in perspectives about the clinicians' orientation to change and role in setting the change agenda is significant, for it also reveals differences in the time-frames of the two groups. The clinicians tended to see contemporary changes as part of an historical cycle while managers had a much shorter time frame both in terms of history and the future (of course, most managers had been in post for a much shorter time). Furthermore, whether a group is perceived and labelled as a detractor or supporter of change is likely to shape relations and negotiations with that group. The degree of actual or perceived difference is also important to gauge in the resolution of any conflict. In the instance of care in the community and hospital closure decision, the comments would indicate that the two groups, clinicians and management, might be closer in principle than is publicly acknowledged, with disputes being much more tied to operationalisation, timing and control.

Perhaps on both sides there has been insufficient attention paid to an explicit analysis of the parameters of conflict. For some doctors there clearly existed a contradiction between their pioneering professional behaviour which had led to much deinstitutionalisation and their 'conservative' response to the management action which aimed to accelerate this process. Managers, it would seem, did not always perceive these tensions or respect them and again this could be explained by the urgency of their task. The bottom-line was that, for the managers, the task was time-limited: to close the hospital by 1992 and to have an infrastructure of community care schemes in place. The clinicians were not driven by or audited on time imperatives. They also found it difficult to have to work to a received time-schedule, which they considered to be politically or managerially determined rather than professionally informed. The perceived distance of the local doctors from the strategic decision of if and when the hospital would close is summarised by one clinical team chairman:

"The story that goes round is that the $\mathrm{Re}$ gional Chairman gave a verbal undertaking to the Secretary of State that he could close the hospital in ten years. ... He had to have a time limit. I think the general perception is that the time limit that was given was not given with a view to considering the problems inherent in the task... That in itself led to quite a lot of initial resentment."

Consultant Psychiatrist 
While local clinicians clearly felt constrained by an externally imposed deadline this was the case for the local managers, too: although it was not explicitly addressed as a shared issue but more typically became an 'us' and 'them' struggle.

A number of the clinicians interviewed also felt that they had learned to take a longer view of change than managers because they had experienced broken management promises and had been victims in the past of managerial or political fashions. One consultant expressly declared that doctors ought not to be risk takers and that their conservatism and application of routine was fitting and proper. On the other hand, managers felt that the slow pace of service change was in part attributable to the dalliance of doctors and their attenuation to narrow professional self-interests.

\section{What are the change objectives and change rationale?}

One of the problems with implementing longstanding national policy and translating these objectives into a local context is that organisations may feel that there is no need for a rehearsal of these policies, aims and objectives. At one level the philosophy and direction is prescribed and circumscribed. The local district or unit's task is to 'make it happen'. However, in the present case study, questions did arise about what were the precise changes to be achieved and why should they be achieved. It could not be assumed that the way forward was clear nor could agreement on the shape of the change be taken for granted or assured. Certainly, the clinicians raised these fundamental questions about strategic direction repeatedly. They felt that there were many unanswerables contained within regional and national directives. Areas of uncertainty included both aspects of deinstitutionalisation and of care in the community. The closure of the hospital provoked questions concerning: the loss of the concept of asylum and protection for vulnerable people; the dilution of expertise with the dispersal of trained staff; the loss of economies of scale; the ordering of the reduction in services with acute services being the last to move; and the management of the interim service.

The reprovision of alternative services also raised many unknowns, including questions about the ideal shape of a comprehensive, community psychiatric service; provision for certain categories of patient (elderly, severely ill; new long-stay; high dependency; patients with behavioural problems); the issue of compulsory treatment; staffing recruitment and training; staff ratios and mix in the community; the community's receptivity to the mentally ill; interorganisational relationships; management capability and the constancy of government policy. Local man- agement was reported as seemingly paying too little attention to these imponderables and as minimalising the expressed lack of clarity or uncertainty. Some brief comments from clinicians illustrate their anxiety about poor definition of objectives:

\begin{abstract}
"A lot of people leading this exercise are purporting to have no vision of it. They don't know what it will be like. They have no concept of how they will run a comprehensive psychiatric service or manage it."

"There is a certain amount of uncertainty as to what we're expected to do. We are not clear what the new service should look like."

"There is a general sense that it (the closure) is not being done properly because of ignorance on the part of everybody concerned. And a general impression that those areas where it has been tried, or where it has gone a bit further along the road, haven't been successful, that they haven't successfully closed a mental hospital, a big one."

"In this exercise we have not been given anything to look forward to. There is nothing we can put a finger on and say see that's the sort of thing to go for. That's not there. The whole thing lacks motivation."
\end{abstract}

Consultant Psychiatrists

As far as the 'why' questions, consultant psychiatrists were often suspicious of the motives and reasons behind the urgent drive to community care and hospital closure. As already explained, they felt divorced from the original decision of when to close and, while not necessarily disagreeing with that decision, felt disempowered thereafter. A clinical team chairman explains:

"The mistake was in reaching the decision
to shut the hospital, the Region failed to get
the people on the ground floor on their side.
And they have had an uphill task persuad-
ing them whether they like it or not, this
place is going to close, so you can knuckle
under or cooperate."
Consultant Psychiatrist

They reported receiving mixed and muddled messages from the various management tiers involved in the process: where on the one hand, they were being given a directive to comply with the closure decision and on the other, asked to develop a shared vision of the way forward. At one extreme this could lead to feelings of powerlessness, and a sense of being an inconsequential part of a grander master plan. One 
consultant saw the Regional Health Authority as part of this distant conspiracy:

"I think it would be more comforting to have more regular contact with Region, at least to get an idea of what they're thinking about because it feels like the fantasy verging on paranoia at times. The fantasy is that the Region has got all kinds of plans for us and they are busy working away and not telling us what they are doing."

\section{Consultant Psychiatrist}

There were also expressions by doctors of fear of political manipulation with cost-efficiency motives dominating quality of care motives. In this scenario doctors felt themselves to be the patients' dispassionate champion and advocate, protecting patients from political vagaries and excesses. Those interviewed gave several examples of where they saw themselves as the altruists and the managers were deemed the villains of the piece. Performance-related pay for managers and short contracts were perceived by the consultants as further evidence of suspect managerial motivation. One doctor puts this distrust in a nutshell:

"The pressure (to close) is coming ultimately from the government, from whatever government of the day motivated by financial considerations I suppose. I think the government would press on the Region and the Region on the District and the District on the UGM. It's his job on the line. He's not been appointed to run a hospital, he's been appointed to close it."

Consultant Psychiatrist

The managers in this study were not unconcerned with objectives and motives and, like the doctors, recognised the need to flesh out national and regional guidelines and expectations for their own service. At an early stage the Unit General Manager asked all the clinical teams to determine their vision of the service and rightly diagnosed the need to involve the clinicians in the forward planning of the reprovided service. However, at this stage one of the frustrations the managers encountered was a lack of coherence in the answers from the clinical teams. In many instances the questions posed by managers were met with questions and not answers. This is an example of where perhaps managers underestimated the amount of time or energy needed to secure the clinicians' 'ownership' of the problem. It was natural that managers would seek clarity, but perhaps they could have paused longer at this phase and helped to steer and influence the answers. Their expectations of the professionals' ability to deliver were very high and perhaps unrealistic. One Regional Officer felt that management had to take some responsibility for having rushed toward implementation before the community of consultant psychiatrists were persuaded of the efficacy of the strategy and in his words "the idea got way out in front and implementation was seen in terms of implementing the idea, rather than a propaganda campaign on a particular constituency." Local managers, in his view were constrained by the fact that the Region itself had misjudged this part of the change process and had neither allowed time for it, nor budgeted for it, nor invested in it. There was an expectation that "you get a concept of a different service and you expect it to gather its own momentum".

This tension between securing a clear idea of where one is going and "getting there" characterised this whole change process during the field-work period and was never fully resolved or rescued. Although variable progress could be made toward a shared vision, managers reported that they lacked clear direction from doctors, and equally doctors from managers and policy makers. Managers found that it was difficult to wait for a consensus to be achieved or a lead to be taken, given the time constraints on the exercise. The managers gave the impression of having to work actively to secure the cooperation of consultants in objective-setting and expressed some irritation and impatience with their seeming lack of commitment and contrariness. This management dilemma is revealed below:

"The cooperation of the clinicians is one of the most problematic. We do need ideally the total partnership of understanding. Now there is evidence and it's not just here, it's pretty much nationwide, that demonstrates that psychiatrists have extremely varying views about the relevance of 'Care in the Community' as a concept of care. And there is no doubt that you can talk to ten psychiatrists and get an entirely different viewpoint when you discuss that issue."

District Officer

"I feel strongly that until you do have a common understanding of what is this service for, who are our clients, what is the role of respective groups of providers, it is actually very difficult to plan services. I feel as if I am working in a reactive environment."

Unit Officer

Consequently, there was a temptation to want to bypass the doctors and find other more ready allegiances to enable the community provision to be established and the hospital to reduce in size. The 
clinicians' preoccupation with questions about fundamental objectives and indeterminancy could be seen as obstinacy and medical hegemony; and indeed could be used either to stall management action or assert medical authority. Here the intention is not to endorse the legitimacy of the behaviour of either party but to map out their competing perspectives. One can respect both clinical caution and the management expediency and appreciate how blockages to progress occur if these differences are not managed and balanced.

The managers in this case study were still trying to get joint objectives agreed and implemented and had devised different methodologies, ranging from working with selected 'progressive' clinicians through to the more extreme solution of overruling clinicians in the taking of key decisions. Needless to say, these tactics met with varying degrees of success and the occasion of overt confrontation concerning a ward closure left a legacy of bad feeling and was seen as further polarising of management and the medical staff. Use of the clinical teams to influence planning and the creation of a strengthened medical representation on the unit management board were two crucial mechanisms in trying to reconcile management and medical ideals. At the time of the research fieldwork these arrangements were still fairly novel and immature and teams had progressed unevenly.

Interestingly, the data show that the distrust expressed by doctors of management in this change exercise was mutual. While the doctors saw the managers as careerist, bonus-seeking, and individualistic, the managers, on the other hand, saw doctors as motivated by self-interest, as bed-greedy, hospitaloriented and imperialist in their determination to keep other caring professionals and agencies out of care of the mentally ill. The effects of these adverse perceptions surfaced and were fuelled more readily in crises, with conflict laid on conflict. There was little evidence of these prejudices being explicitly addressed or of any trust-building initiatives in this case study. However, one of the unit managers in a receiving district felt that the problem of poor management image and credibility and of medical dissonance had been partially resolved through a mixture of confrontation, joint problem-solving and results. Unless tackled positively, these negative images of the two groups could prove lasting impediments as the organisation approaches critical decision-points. They certainly did not enhance or enable the building of a joint vision of the future or the development of a corporate 'mission statement'.

\section{Making the change happen}

Another acute point of difference between the managers and the clinicians could be seen at an operational level. Although it may seem obvious that doctors and managers have different jobs they may not always understand the scope or nature of those jobs and the congruent orientations that these bring. This could lead to each undervaluing the other's input.

The managers in this case study found themselves with three major and not easily prioritised tasks: ward rationalisation to facilitate closure; managing an interim hospital service; and planning alternative provision in the community. Sometimes it was not clear which of these tasks was in the ascendancy or even possible to appreciate their close interdependency. They all required detailed planning, costing and intensive managerial effort. The scale and complexity of the managers' task is embraced in the following list of initiatives undertaken during the first 18 months of the UGM and his team being in post: development of a costed retraction model; ward closures to achieve cost-savings; preparation of a manpower policy and redeployment questionnaire; establishment of an information base and communications strategy; comprehensive patient assessments; production of plans for care in the community schemes; and this all overlaid by fundamental changes in management arrangements post-Griffiths. New relationships had to be forged internally and externally with clinicians being only one among many interest groups and included Unit-District, Unit-Region, inter-District, local authority and voluntary sector dimensions.

In addition, they were faced with implementing many national priorities: for example, privatisation of support services and introduction of information systems. In this respect the manager's task is both more diffuse than that charged of the clinician and requires more active incorporation of network, extra- and inter-organisational effects. At an operational level doctors deal with individuals and conditions while the manager has to deal with collectives and systems. This could lead to managers feeling doctors were only concerned with 'bodies and beds' or vice versa that managers were obsessed with structures, plans and finance. It could also spawn very different sorts of questions and concerns on a day to day basis. The barriers between the two groups could be reinforced because of this failure to understand the other's everyday world. This imperative for managers to relate to a wide constituency meant that of necessity they had at times to question and balance differing group interests and even to challenge medical supremacy. It was not simply a case of 'us' and 'them' but of 'them' and 'them'. Some of these questions about how the service pieces and responsibilities fit together are posed by a unit officer and illustrate nicely the management remit:

"What is mental health?...We keep talking about mental health instead of 
psychiatric services. So what is the Health Authority's role? What are others doing? What is the size of the problem? There are problems of liaison with local authorities because they have different approaches. What is the role of the voluntary sector? What is the role of psychotherapy? What is the role of psychologists?"

\section{Unit Officer}

While clinicians may ponder these sorts of questions, it is not their business to do so nor are they compelled to find practicable solutions. This is tightly written into the manager's job description and the success of an alternative service will rest on the strength, quality and shape of these connections.

The accountability issue can also not be overlooked and, as was indicated earlier, doctors and managers fall into very different chains of authority. While managers felt their own line had been tightened with the introduction of general management, this was perceived as having little effect on doctors. This was felt to create an inequity at an operational level where well-laid plans could be thwarted or undermined either overtly or by stealth. After general management, doctors were the only group with this impunity and, while it may cause few organisational problems in times of expansion and development, it could heighten antagonisms in times of contraction or retrenchment. Furthermore, the clinicians interviewed here admitted that they felt very inexperienced in management and were either ill-trained or ill-fitted for managerial responsibilities. They recognised that they often disappointed managers when they were asked to take a more active or proactive managerial role. There was too some confusion over the representative role of the clinician and how far that clinician could be tied into a managerial line and corporate management group. Could this clinician 'deliver' his colleagues and should he be able to? Managers and clinicians expressed mixed expectations.

In this case study, gaining the cooperation of the clinicians was seen as an important part of the exercise, as has already been shown; but management had to rely on non-directive techniques. However, there were those who commented that opportunities had been missed and who felt that salvation lay not in tying the clinicians into an accountability structure but through education and a 'political campaign' to 'sell them stocks and shares in the mission'. Following this version of thinking, the Region in this instance did try to break down the managementclinician divide and in a fairly recent innovation recruited a consultant psychiatrist to act as a change agent and mediator. This was seen as a way of circumventing the hierarchy issues, the accountability issues, and of stimulating commitment from within to the projected change. It was also a recognition based on feedback from the District that some of the early steps in the change process may have been skipped or hurried. Some feel it may already be too late to go back to first base. How far this initiative succeeds in its objective is not possible to evaluate at this stage of the research but it does indicate that at one level the clinician-management interface is being treated seriously and creatively. The findings reported here may further inform this exercise and others of its kind.

\section{Deinstitutionalisation: managing the context}

As well as showing the importance of management process issues in achieving change, the data gathered in this research project indicate that it would be naive to introduce a radical service change without a positive acknowledgement or awareness of the context and historical evolution of the service being dismantled. ${ }^{4}$ This attentiveness to the past and the reading of the contextual cues would appear to be a vital part of managing the future. The following features emerged as significant and we suggest that these antecedent conditions can be isolated and managed. Some are generic and relate to all large psychiatric institutions while others are specific to the case study.

From the outset it would seem that in planning for change, express consideration needs to be given to the asylum as a particular historical and cultural form, marked by all the characteristics of a total institution designed to provide custody, containment, isolation, protection and more recently, treatment. The majority of the patients in asylums tend to be long-stay, chronically ill and elderly. Goffman ${ }^{11}$ observed that such institutions enshrine many patient management rules which were primarily for "the comfort and convenience of staff" (ibid: 302). This raises the issue of an institutionalised workforce as well as patients. In Goffman's view one of the "central effects of such institutions is to sustain the self-conception of the professional staff who work there" (ibid: 334). He argues that asylums are strongly mandated by the public who take comfort from their being there to exile and contain "mad people". The public in his view were happy to hand over this problem to doctors and medicalisation meant that liberal consciences could be salved. Asylums also depend on occupational communities with patterns of generational and inter-household employment. There tends to be lengthy tenure and little geographic mobility at least of middle and junior staff. All these factors will be suggestive of the organisation's receptivity to change, and experience of change, and indicative of which are the influential groups in the change process: the patient population; the staff and the public. 
The findings suggest that the place of consultant psychiatrists in the status/skill hierarchy of mental health care workers and the historical evolution of psychiatric medicine and the allied professionals also merits reflection. In the transition away from custodial care there are implied changes to these relationships and rankings. This will be discussed further in the final section of the paper. The special relationship between nurse and doctor in an institutional context may also deserve recognition. With the current trend to move acute psychiatry to District General Hospitals the historical relationship between physical medicine and psychiatric medicine could prove relevant.

Some grasp of the time scale and the complexity of the process by which the care of the mentally ill became regulated by the state would seem essential. This would help to inform those preparing for change about the length of service change cycles. Why was an institutional asylum-based model developed and preferred? What were the sociological and historical factors which provoked this particular configuration of care? $?^{12,13,14}$ The important question leading on from this for change agents is why is this form being challenged and replaced by a non-segregative, community-based response. This requires a corresponding appreciation of the policy context and an assessment of the direction from which the change springs.

Interviews with long-serving staff show that the particular managerial traditions of asylums need to be remembered in the change management process. Many staff recalled a very hierarchial, even authoritarian, management process and were not unaccustomed to having executive authority invested in one individual, typically a medical superintendent. General management was not felt to be an entirely new or unfamiliar concept although executive authority no longer ensured medical supremacy in the new era. However, this would suggest that many asylum staff may at some time have experienced strong leadership, delegation and control.

Previous experience of management, past management successes or failures also emerged from the case study as important. Organisations like asylums seem to have 'memories' and certainly relate a strong folklore, where management feature as good or bad fairies. The organisation's own self-image appears as vital, combined with the image held by others. In this case study many of those interviewed wanted to correct what they felt was an unjustly damaging image. The response of management to this interplay will be important during change.

The corollary of this of course is that significance will also attach to the profile of industrial relations in the changing organisation. The emergence of unionisation, relationships between unions, the pattern of industrial action and disaffection all need careful reading.
The quality and nature of relationships with external agencies and with significant other internal tiers has to be taken seriously in managing this particular service change which is highly dependent on shifting responsibilities from one carer to another. This implies the need for understanding different cultural traditions and practices. A wider perspective on the evolution and rationale of these associated organisations and structures is required. Managing this outer context will imply spotting potential conflicts, conceptual differences and competing priorities. Questions arose in this study concerning the role of experts and professionals vis $a$ vis lay carers in the future service. The concept of the patient or client and assessment of his/her need was also highly problematic. Change leaders will have to face the decoding, translating and integrating of a collection of relevant contexts and histories. The political dimension impinges here.

Although difficult to quantify, our analysis would indicate that the organisation's 'change biography', in other words its previous exposure to radical change, is part of important background data. Too much change, or change laid upon change, may influence the next wave. ${ }^{4}$ Equally, a conservative, changeresisting organisation will pose different sorts of problems to those charged with achieving change.

\section{Deinstitutionalisation: what will it mean for consultant psychiatrists?}

In any change process, however it is managed and whatever the context, there will be losses and gains for those centre stage. In this research there was an opportunity to canvass what consultant psychiatrists, as part of the principal cast, thought would be the effects of deinstitutionalisation and the move to care in the community on their roles. It will only be possible to deal briefly with their responses here but it is hoped to develop these findings in a later paper.

Not surprisingly, opinions differed and not everyone felt that substantial changes would occur in their own role. This was conditional on the balance and style of their present activity. However, some interesting themes did emerge and there was a recognition that status and medical primacy issues were at stake. The chairman of one clinical team commented that:

"I think nurses are going to take on a lot more responsibility. I think to that extent physicians are going to have to lose some of their autonomy, some of their mystique I suppose. Doctors are pig-headed, they like to think they can manage it all themselves."

The issue of clinical responsibility was also raised in the community setting and there was some feeling 
that this was unresolved. There was expressed uncertainty about who would be answerable when things went wrong. Institutions were seen as providing failsafe mechanisms and clear control procedures. There was also no ambiguity about the doctor's position in the skill hierarchy in an institutional setting. At its extreme, this issue could be seen as moving from a posture of damage-limitation to one of risk-taking. One doctor felt no-one had "grasped this nettle".

The diversification of psychiatry into everincreasing subspecialties was anticipated as a further dimension of deinstitutionalisation; and was not altogether welcomed, especially the trend to move closer to physical medicine. This tendency to emulate physicians was criticised by one respondent who thought it was a case of psychiatrists "buying the wrong script". He largely attributed this phenomenon to the transfer of services to District General Hospital sites and felt that it ought to be the psychiatrists influencing the other practitioners "to get a lot more psychologically oriented than they are".

Interestingly, none of the doctors in this particular case mentioned the issue of the deskilling of clinicians as other professionals develop their expertise. All assumed they would have a place in the new service, even if this was a shared part and if their autonomy was reduced. While this discussion about the demedicalisation of mental health occurs elsewhere, these doctors felt their stake was still strong and expressed a confidence in their tenure in a community-based service. One interviewee went so far as to class the anti-psychiatry movement as passé and felt the debate about whether mental illness was 'real' had ended. The clinicians here felt secure in their professional futures and unthreatened by what might seem to others as deregulation of their service. Looking back to the earlier part of this paper on the management-clinician relationship, it is worth commenting that managers interpreted many of the stances adopted by doctors as being about this precise issue. They saw the medical profession as behaving defensively, guarding territory, and warding off perceived attempts to unseat them. The doctors, in contrast, did not admit to this power struggle or see the likelihood of being disenfranchised in any real sense.

\section{Comments}

This paper has shown that any radical service change will involve competing interest groups and is in essence a political process. ${ }^{4,10}$ One of the important parameters is the balance between clinical and management perspectives. These two groups may not always appreciate or respect each other's position and a polarisation may occur. By articulating some of these points of conflict, management, it is argued, may better grasp the change process. A deliberate strategy on handling internal differences could prevent problems becoming personalised or particularised. One of the crunch points in this case study concerned whether the change was perceived as clinician-led or management-led; and indeed, clinicians never felt properly scripted in to the proposed hospital closure decision. This failure to incorporate such a crucial constituency, that is, the consultant psychiatrists, into the primary strategic decision resulted in much lasting confusion, ill-will and delay.

Frustration resulted on both sides, with managers wanting to get on with implementing the decision and doctors wanting to question the rationale behind the decision, as well as fielding nitty-gritty questions about service direction. Other differences emerged in relation to time-scales, motives, day-to-day preoccupations, and lines of accountability: all of which could create a communication gap and enhance levels of mistrust. This could at best lead to missed opportunities in advancing the change and at worst to backlash and breakdown in relations.

Positive management in such a political environment would imply the need for managers to find ways of building bridges with clinicians and gaining their commitment to the change objective. This commitment should not be taken for granted but secured through direct and deliberate means. Tactics such as influencing by example or education, working with more influential or pioneering clinicians, bringing in innovators from outside and providing a system of rewards and incentives for the participation of the clinicians would all need to be tried. Treating clinicians' fears and questions about the future service seriously would seem to be a prerequisite of good management in this context. Some features of general management, with its task- and target-centred emphasis and its short-term contracts, may seem to militate against these more diffuse, unmeasurable political objectives. However, it would seem that longer-term success may be forfeited if managers underestimate the potency of those who have the capacity to veto the new vision and who, after all, are entitled to a major, if reduced, stake in it.

As well as the active management of these process factors, the context in which change is to be implemented needs evaluating. Each organisational change will have its own peculiar history and unique blend of circumstances. These are not unfathomable and can be itemised and codified, if only crudely. Organisations have their own informants who can provide some of this evidence. Researching the context is likely to pay dividends, for closing a large psychiatric hospital cannot be simply compared with the process of closing a needle factory. Culture, tradition and values are all influential. Where management resource is scarce there may be a 
temptation to get action plans in place and to hasten towards their implementation. This can lead to a lack of depth in such plans and to plans which are culturally inappropriate. Managers should invest time in decoding their environment and in finding out its internal logic and history. This is a proper and legitimate part of the management of change and each organisation or institution will have its scars and skeletons, its trophies and triumphs.

Deinstitutionalisation of psychiatric care is said to hit at the power base of psychiatric medicine and to unseat the medical hold over mental health and care of the mentally ill. Care in the community will bring many other agencies, both statutory and voluntary and many other carers, both professional and lay, into the arena. While clinicians themselves expect some modification to their role, those interviewed in this study did not expect to depart radically from previous practice, or indeed to lose any of their security of tenure. They expected to remain major stake holders in the changed service. This leads to questions about how far clinicians are being prepared for change and how ready they are to be managed through change. Training/retraining policies for other care groups are much more commonplace; nurses especially have been offered opportunities to review their future roles. How many clinicians, in contrast, have had constructive time out for reflection upon where they are going? Such exploration of the future would provide a common challenge for both managers and clinicians, but it needs to be done creatively and respectfully and not reactively or dismissively.

\section{Acknowledgement}

I am grateful for the comments of my colleagues Professor Andrew Pettigrew and Dr Ewan Ferlie at the
Centre for Corporate Strategy and Change, University of Warwick Business School; and of course most of all for the insight, time and unstinting co-operation of the staff of the hospital, District, and Region involved. The research is financed by a grant from the NHSTA and from eight regions of the NHS in England.

\section{References}

${ }^{1}$ Audit Commission (1986) Making a Reality of Community Care. London: HMSO.

${ }^{2}$ Hunter, D. \& Wistow, G. (1987) Community Care in Britain: Variations on a Theme. London: Kings' Fund.

${ }^{3}$ Korman, N. \& Glennester, H. (1985) Closing a Hospital. London: Bedford Square Press.

${ }^{4}$ Petrigrew, A. M. (1985) The Awakening Giant: Continuity and change in ICI. Oxford: Basil Blackwell.

5 _ MCKeE, L. \& FERLIE, E. (1988) Managing organisational change in the NHS, Public Administration, (to be published in September 1988).

${ }^{6}$ CYERT, R. M. \& MARCH, J. G. (1963) A Behavioural Theory of the Firm. Englewood-Cliffs: Prentice-Hall.

'Pettigrew, A. M. (1973) The Politics of Organisational Decision-Making. London: Tavistock.

${ }^{8}$ Thompson, D. (1987) Coalitions and conflict in the National Health Service: Some implications for general management, Sociology of Health and Illness, 9, 127-153.

${ }^{9}$ STOcking, B. (1985) Innovation and Inertia in the NHS. London: Nuffield Provincial Hospitals Trust.

${ }^{10}$ HARDY, C. (1985) The Management of Organisational Closure. Aldershot: Gower.

${ }^{11}$ Gofrman, E. (1961) Asylums. London: Pelican.

${ }^{12}$ Foucault, M. (1971) Madness and Civilisation. London: Tavistock.

${ }^{13}$ Scull, A. T. (1984) Museums of Madness - the Social Origins of Insanity in Nineteenth Century England. London: Penguin.

${ }^{14}$ Busfield, J. (1986) Managing Madness: Changing Ideas and Practice. London: Hutchinson. 